\title{
Effects of CYP2B6 G516T polymorphisms on plasma efavirenz and nevirapine levels when co-administered with rifampicin in HIV/TB co-infected Thai adults
}

Sumonmal Uttayamakul ${ }^{1,2}$, Sirirat Likanonsakul ${ }^{2}$, Weerawat Manosuthi ${ }^{2}$, Nuanjun Wichukchinda ${ }^{3}$, Thareerat Kalambaheti ${ }^{1}$, Emi E Nakayama ${ }^{4}$, Tatsuo Shioda ${ }^{4}$, Srisin Khusmith ${ }^{1^{*}}$

\begin{abstract}
Background: Cytochrome P450 2B6 (CYP2B6) metabolizes efavirenz and nevirapine, the major core antiretroviral drugs for HIV in Thailand. Rifampicin, a critical component of tuberculosis (TB) therapy is a potent inducer of CYP enzyme activity. Polymorphisms of CYP2B6 and CYP3A4 are associated with altered activity of hepatic enzyme in the liver and pharmacokinetics resulting in treatment efficacy. This study aimed to investigate whether CYP2B6 or CYP3A4 polymorphisms had effects on plasma efavirenz and nevirapine concentrations when co-administered with rifampicin in HIV/TB co-infected Thai adults.

Results: We studied 124 rifampicin recipients with concurrent HIV-1/TB coinfection, receiving efavirenz (600 mg/ day) $(n=65)$ or nevirapine (400 mg/day) $(n=59)$ based antiretroviral therapy (ART). The frequencies of $G G$, GT and $\Pi$ genotypes of CYP2B6-G516T were 38.46\%, 47.69\% and 13.85\% in efavirenz group and $44.07 \%, 52.54 \%$ and 3.39\% in nevirapine group, respectively. The mean 12-hour post-dose plasma efavirenz concentration in patients with $\pi$ genotype at weeks 6 and 12 of ART and 1 month after rifampicin discontinuation $(10.97 \pm 2.32,13.62 \pm 4.21$ and $8.48 \pm 1.30 \mathrm{mg} / \mathrm{L}$, respectively) were significantly higher than those with GT $(3.43 \pm 0.29,3.35 \pm 0.27$ and $3.21 \pm$ $0.22 \mathrm{mg} / \mathrm{L}$, respectively) $(p<0.0001)$ or $G G$ genotypes $(2.88 \pm 0.33,2.45 \pm 0.26$ and $2.08 \pm 0.16 \mathrm{mg} / \mathrm{L}$, respectively) $(p<0.0001)$. Likewise, the mean 12-hour post-dose plasma nevirapine concentration in patients carrying $\Pi$ genotype at weeks 6 and 12 of ART and 1 month after rifampicin discontinuation (14.09 $\pm 9.49,7.94 \pm 2.76$ and $9.44 \pm 0.17 \mathrm{mg} / \mathrm{L}$, respectively) tended to be higher than those carrying GT (5.65 $\pm 0.54,5.58 \pm 0.48$ and $7.03 \pm$ $0.64 \mathrm{mg} / \mathrm{L}$, respectively) or GG genotypes $(5.42 \pm 0.48,5.34 \pm 0.50$ and $6.43 \pm 0.64 \mathrm{mg} / \mathrm{L}$, respectively) $(p=0.003$, $p=0.409$ and $p=0.448$, respectively). Compared with the effects of CYP2B6-516TT genotype, we could observe only small effects of rifampicin on plasma efavirenz and nevirapine levels. After 12 weeks of both drug regimens, there was a trend towards higher percentage of patients with CYP2B6-TT genotype who achieved HIV-1 RNA levels $<50$ copies $/ \mathrm{mL}$ compared to those with GT or GG genotypes. This is the first report to demonstrate the effects of CYP2B6 G516T polymorphisms on plasma efavirenz and nevirapine concentrations when co-administered with rifampicin in HIV/TB co-infected Thai adults.
\end{abstract}

Conclusions: CYP2B6-TT genotype had impact on plasma efavirenz and nevirapine concentrations, while rifampicin co-administration had only small effects.

\footnotetext{
* Correspondence: tmskm@mahidol.ac.th

'Department of Microbiology and Immunology, Faculty of Tropical Medicine, Mahidol University, Bangkok, Thailand
} 


\section{Background}

Tuberculosis (TB) is the most common opportunistic infections in human immunodeficiency virus (HIV) infected individuals, accounting for more than $30 \%$ in Thailand, and up to $50 \%$ of them die during treatment [1]. The mortality is reduced in HIV-TB co-infected patients who have started the combination antiretroviral therapy after diagnosis of TB [2]. Concomitant administration of highly active antiretroviral therapy (HAART) and anti-TB medications is often complicated due to the drug-drug interaction and the adverse effect profile. Efavirenz and nevirapine based HAART regimens have mostly recommended to use as components of first-line antiretroviral drug regimens worldwide [3]. As efavirenz and nevirapine are potent non-nucleoside reverse transcriptase inhibitors (NNRTIs), they are the preferable option for initial antiretroviral treatments (ART) in HIV/TB co-infection. Rifampicin is a critical component of TB therapy while it is a potent inducer of cytochrome P450 (CYP) enzyme activity [4]. The available pharmacokinetic data showed that rifampicin reduced the plasma concentration of efavirenz and nevirapine of 13$25 \%$ and $40 \%$, respectively [5-7]. Recently, efavirenz was shown in vitro to be primarily metabolized by hepatic CYP2B6, with minor contributions from CYP3A4 and CYP2A6 $[4,8]$. While rifampicin is an inducer of CYP3A4, nevirapine induces more CYP2B6 than CYP3A4 [9]. Nevirapine was also shown to be principally metabolized by CYP3A4 and CYP2B6 [10]. $C Y P 2 B 6$ and $C Y P 3 A 4$ genotypes are evidenced to be associated with altered activity of hepatic enzyme in the liver and pharmacokinetics that may influence efficacy of treatment, since rifampicin causes decrease in efavirenz and nevirapine concentrations [11-13].

The CYP2B6 and CYP3A4 genes are highly polymorphic [14] and are subject to pronounce interindividual variability in expression and activity. A single nucleotide polymorphism (SNP) at position 516 on the $C Y P 2 B 6$ gene has been widely reported to play an important role in the metabolism of antiretroviral drugs [15-18]. This CYP2B6 genetic variant affects the efavirenz and nevirapine pharmacokinetics $[16,19,20]$ and associated with clinical response to nevirapine-containing regimens in children [16]. Significant advances have led to a greater understanding of interactions between genetic and host factors that influence the efficacy and toxicity of efavirenz $[19,21]$. However, the findings from one population may not be generalised to other populations due to the ethnic differences in drug effect and body weight of the patients. In Thailand, it has been recently reported that CYP2B6-G516T polymorphism significantly affected the drug metabolism of efavirenz in HIV-infected Thai children [22], while its impact on nevirapine concentrations was less pronounced after intra-partum single-dose nevirapine in HIV-infected mothers [23]. As efavirenz or nevirapine-based HAART is being used as the main therapy in Thailand, however, limited information was obtained so far among various Thai population regarding the influence of host genetic polymorphism on these drug levels especially nevirapine when co-administered with rifampicin which is essential for optimization of ARV dosage or drug-drug interaction. Therefore, the main objective of the present study is to investigate whether $C Y P 2 B 6$ and $C Y P 3 A 4$ polymorphisms could influence the plasma efavirenz and nevirapine levels when co-administered with rifampicin in HIV/TB infected Thai adults. The evaluation of clinical and immunological outcomes was also aimed.

\section{Methods \\ Patients}

One hundred and twenty four rifampicin recipients with concurrent HIV-1/TB coinfection were studied. Sixtyfive of them received efavirenz ( $600 \mathrm{mg} /$ day) based ART while 59 received nevirapine $(400 \mathrm{mg} /$ day) based ART. Initially, 142 patients were recruited for the study on a randomized control trial to compare the efficacy of efavirenz and nevirapine among HIV-infected patients receiving rifampicin at Bamrasnaradura Infectious Diseases Institute (BIDI), Nonthaburi since December 2006 [24]. They are ARV naïve with active tuberculosis and received rifampicin containing anti-TB regimens for 4-6 weeks prior to enrolment. The patients received oral lamivudine $(150 \mathrm{mg}$ ) and stavudine $(30 \mathrm{mg}$ for those who weighed $\leq 60 \mathrm{~kg}$ and $40 \mathrm{mg}$ for those who weighed $>60 \mathrm{~kg}$ ) every 12 hours. They were randomized to receive either efavirenz $600 \mathrm{mg}$ at bedtime while fasting or nevirapine $200 \mathrm{mg}$ every 12 hours after 2 weeks at a starting dose of $200 \mathrm{mg}$ every 24 hours. The dosage of rifampicin was $450 \mathrm{mg} /$ day for patients who weighed $\leq$ $50 \mathrm{~kg}$ and $600 \mathrm{mg} /$ day for those who weighed $>50 \mathrm{~kg}$. The anti-TB drug regimen was isoniazid, rifampicin, ethambutol and pyrazinamide for the first two months, followed by isoniazid and rifampicin for the subsequent 4-7 months. Among 142 patients recruited, 25 patients (9 in the efavirenz group and 16 in the nevirapine group) failed to continue the study because of hepatitis ( 2 cases in the nevirapine group), skin rash (3 in the efavirenz group and 2 in the nevirapine group), death ( 2 in the efavirenz group and 6 in the nevirapine group), transfer to the other hospital (1 in the nevirapine group), or lost to follow up ( 4 in the efavirenz group and 5 in the nevirapine group). In the present study, we analyzed 124 patients who have a complete data set of plasma drug levels at week 6 and 12 of ART and 1 month after rifampicin discontinuation. The study was approved by Institutional Ethics Committees of Bamrasnaradura Infectious Diseases Institute and the Ministry 
of Public Health, Thailand and the written informed consents were obtained from all participants.

\section{Blood samples}

EDTA bloods were collected from patients for SNP genotyping, CD4 T cell counts and HIV-1 viral load. Lithium heparinized bloods were collected after 12 hours of drug administration $\left(\mathrm{C}_{12}\right)$ at weeks 6 and 12 of ART and after rifampicin discontinuation for 1 month for analysis of plasma efavirenz and nevirapine concentrations. The plasma were separated by centrifugation at $1800 \mathrm{~g}$ for 20 minutes and stored at $-20^{\circ} \mathrm{C}$.

\section{SNP genotyping of CYP2B6 and CYP3A4}

The genomic DNA was extracted by using QIAamp DNA blood Mini kit (QIAGEN, Hilden, Germany) and stored at $-20^{\circ} \mathrm{C}$ for SNP genotyping. Genotyping of allelic variants in $C Y P 2 B 6$ and $C Y P 3 A 4$ were carried out by real-time PCR using the allelic-specific fluorogenic 5' nuclease chain reaction assay by ABI PRISM 7500 sequence detection system (Applied Biosystems, Foster City, CA) as described previously [15]. Seven SNPs were genotyped: 4 SNPs of CYP2B6-G516T, -C777A, -A415G and $-\mathrm{C} 1459 \mathrm{~T}$ and 3 SNPs of CYP3A4-T566C, -T878C and C1088T. Each $25 \mu \mathrm{l}$ PCR mixture contained $20 \mathrm{ng}$ of genomic DNA, $900 \mathrm{nM}$ primers, $200 \mathrm{nM}$ TaqMan minor groove binder (MGB) probes and $12.5 \mu \mathrm{l}$ TaqMan universal PCR master mix. The thermal cycler program was set up at $95^{\circ} \mathrm{C}$ for 10 minutes, and then repeated 40 cycles with $95^{\circ} \mathrm{C}$ for 15 seconds and $60^{\circ} \mathrm{C}$ for 1 minute. The plate was read by the allelic discrimination settings. The SNP assay was set up using SDS, version 1.3.0 as an absolute quantification assay. Post-assay analysis was done by using SDS software.

\section{Determination of plasma efavirenz and nevirapine concentration}

Plasma efavirenz and nevirapine concentrations were measured by reverse phase high performance liquid chromatography (HPLC) method at the HIV-Netherlands-Australia-Thailand (HIV-NAT) Research Pharmacokinetic Laboratory, Chulalongkorn Medical Research Center (Bangkok, Thailand). HPLC was performed in accordance with the protocol developed by Department of Clinical Pharmacology, University Medical Center Nijmegan (Nijmegan, the Netherlands) [25].

\section{CD4 T lymphocyte counts and plasma HIV-1 RNA quantitation}

The CD4 T lymphocyte counts were done at baseline and every 12 weeks after initiation of antiretroviral treatment by flow cytometry using monoclonal antibodies with three colors reagent (TriTEST, Becton Dickinson BioSciences, USA) and analyzed by FACScan flow cytometer (Becton Dickinson BioSciences, USA.). Plasma HIV-1 RNA was determined by RT-PCR at baseline and every 12 weeks after initiation of ART and quantified using the COBAS Amplicor, version 1.5 (Roche Diagnostics, USA). The lower detection limit for HIV-1 RNA level is 50 copies $/ \mathrm{mL}$.

\section{Statistical analysis}

The different genotypes in relation to plasma drug levels were analysed by SPSS software version 14.0 (ID 5038562) (SPSS Inc., Chicago, IL, USA). If unpaired one-way analysis of variance (ANOVA) was significant $(\mathrm{p}<0.05)$, then post hoc Scheffe's $F$ test was applied for multiple comparison. When plasma drug levels of different time points were compared, paired $\mathrm{T}$ test was used. The CD4 T cell counts and HIV-1 viral load in patients carrying different genotypes were compared by KruskalWallis test. A difference in proportion of patients who achieved plasma HIV-1 RNA < 50 copies/ml at week 12 of ART was evaluated by Chi square or Fisher's exact test. A $p$ value of $<0.05$ was considered statistically significant.

\section{Results}

\section{Patient characteristics}

The baseline characteristics of patients are shown in Table 1. All 124 patients were ethnically Thai and among these, $64.6 \%$ and $67.8 \%$ were male in efavirenz and nevirapine groups, respectively. The patients had the mean ages of $35.89 \pm 8.17$ and $38.03 \pm 8.60$ years and the mean body weights of $53.30 \pm 9.79$ and $54.39 \pm$ $9.39 \mathrm{~kg}$ in efavirenz and nevirapine groups, respectively. Similar levels of laboratory parameters including alkaline phosphatase, aspartate aminotransferase, alanine aminotransferase, total bilirubin and direct bilirubin were seen in both patient groups. However, the levels of alkaline phosphatase among patients carrying TT genotype in efavirenz group were higher than those carrying GG or GT genotypes, but this difference was not statistically significant $(\mathrm{p}=0.085)$. The median (interquartile range, IQR) CD4 T lymphocyte counts were similar in both groups. In nevirapine treatment group, the log number of plasma HIV-1 viral load among patients carrying GG, GT and TT genotypes seem to be significantly different $(\mathrm{p}=0.041)$.

\section{Frequencies of CYP2B6 and CYP3A4 genetic polymorphisms}

Seven SNPs: 4 SNPs of CYP2B6- G516T, -C777A, -A415G and -C1459T and 3 SNPs of CYP3A4-T566C, - T878C and -C1088T were genotyped. For CYP2B6G516T, 38.46\% (25/65) of GG genotype (wild-type), $47.69 \%(31 / 65)$ of GT genotype (heterozygous mutant) and $13.85 \%(9 / 65)$ of TT genotype (homozygous 
Table 1 Baseline characteristics of 124 HIV/TB co-infected patients with CYP2B6-G516T genotypes in efavirenz and nevirapine groups.

\begin{tabular}{|c|c|c|c|c|c|c|c|c|}
\hline \multirow[t]{3}{*}{ Baseline characteristics } & \multicolumn{4}{|c|}{$\begin{array}{l}\text { Efavirenz group }(n=65) \\
\text { CYP2B6-G516T }\end{array}$} & \multicolumn{4}{|c|}{$\begin{array}{l}\text { Nevirapine group }(n=59) \\
\text { CYP2B6-G516T }\end{array}$} \\
\hline & $\overline{\mathrm{GG}}$ & GT & $\mathrm{TT}$ & p-value & GG & GT & $\pi$ & p-value \\
\hline & $n=25$ & $\mathrm{n}=31$ & $\mathrm{n}=9$ & & $n=26$ & $\mathrm{n}=31$ & $\mathrm{n}=\mathbf{2}$ & \\
\hline Sex Male: Female & 16: 9 & 21: 10 & $5: 4$ & 0.795 & $17: 9$ & 22: 9 & 1:1 & 0.707 \\
\hline $\begin{array}{l}\text { Age } \\
\text { years, mean (SD) }\end{array}$ & $\begin{array}{l}36.48 \\
(8.08)\end{array}$ & $\begin{array}{l}35.68 \\
(8.82)\end{array}$ & $\begin{array}{l}35 \\
(6.63)\end{array}$ & 0.882 & $\begin{array}{l}36.48 \\
(8.08)\end{array}$ & $\begin{array}{l}35.68 \\
(8.82)\end{array}$ & $\begin{array}{l}35 \\
(6.63)\end{array}$ & 0.467 \\
\hline $\begin{array}{l}\text { Body weight } \\
\text { kg, mean (SD) }\end{array}$ & $\begin{array}{l}52.9 \\
(1.87)\end{array}$ & $\begin{array}{l}53.94 \\
(1.89)\end{array}$ & $\begin{array}{l}52.22 \\
(3.04)\end{array}$ & 0.872 & $\begin{array}{l}54.62 \\
(2.06)\end{array}$ & $\begin{array}{l}54.7 \\
(1.52)\end{array}$ & $\begin{array}{l}46.5 \\
(6.5)\end{array}$ & 0.489 \\
\hline $\begin{array}{l}\text { Alkaline phosphatase, } \\
\mathrm{U} / \mathrm{L} \text {, mean (SD) }\end{array}$ & $\begin{array}{l}149.2 \\
(18.38)\end{array}$ & $\begin{array}{l}137.1 \\
(16.91)\end{array}$ & $\begin{array}{l}233.9 \\
(68.45)\end{array}$ & 0.085 & $\begin{array}{l}150.25 \\
(28.9)\end{array}$ & $\begin{array}{l}113.97 \\
(11.1)\end{array}$ & $\begin{array}{l}125 \\
(4)\end{array}$ & 0.458 \\
\hline Aspartate aminotransferase $U / L$, mean (SD) & $\begin{array}{l}32.8 \\
(2.35)\end{array}$ & $\begin{array}{l}40.48 \\
(3.32)\end{array}$ & $\begin{array}{l}43.22 \\
(10.21)\end{array}$ & 0.202 & $\begin{array}{l}48.54 \\
(7.31)\end{array}$ & $\begin{array}{l}35.58 \\
(2.99)\end{array}$ & $\begin{array}{l}26 \\
(1)\end{array}$ & 0.167 \\
\hline Alanine aminotransferase, $\mathrm{U} / \mathrm{L}$, mean (SD) & $\begin{array}{l}27.0 \\
(3.05)\end{array}$ & $\begin{array}{l}28.55 \\
(2.89)\end{array}$ & $\begin{array}{l}31.22 \\
(8.89)\end{array}$ & 0.821 & $\begin{array}{l}29.81 \\
(3.95)\end{array}$ & $\begin{array}{l}27.94 \\
(3.57)\end{array}$ & $\begin{array}{l}23.5 \\
(5.5)\end{array}$ & 0.877 \\
\hline $\begin{array}{l}\text { Total bilirubin, } \\
\text { mg/dL, mean (SD) }\end{array}$ & $\begin{array}{l}4.9 \\
(4.34)\end{array}$ & $\begin{array}{l}0.56 \\
(0.55)\end{array}$ & $\begin{array}{l}0.43 \\
(0.07)\end{array}$ & 0.452 & $\begin{array}{l}2.97 \\
(2.4)\end{array}$ & $\begin{array}{l}1.13 \\
(0.57)\end{array}$ & $\begin{array}{l}0.6 \\
(0.1)\end{array}$ & 0.703 \\
\hline $\begin{array}{l}\text { Direct bilirubin, } \\
\mathrm{mg} / \mathrm{dL} \text {, mean (SD) }\end{array}$ & $\begin{array}{l}0.45 \\
(0.14)\end{array}$ & $\begin{array}{l}0.37 \\
(0.12)\end{array}$ & $\begin{array}{l}0.21 \\
(0.05)\end{array}$ & 0.631 & $\begin{array}{l}0.28 \\
(0.047)\end{array}$ & $\begin{array}{l}0.52 \\
(0.199)\end{array}$ & $\begin{array}{l}0.30 \\
(0.1)\end{array}$ & 0.568 \\
\hline $\begin{array}{l}\text { CD4 count, } \\
\text { cells/ } / \text { l, median (IQR) }\end{array}$ & $\begin{array}{l}41 \\
(18-102)\end{array}$ & $\begin{array}{l}54 \\
(24-120)\end{array}$ & $\begin{array}{l}67 \\
(12.5-168)\end{array}$ & 0.818 & $\begin{array}{l}35.5 \\
(23.5-97)\end{array}$ & $\begin{array}{l}45 \\
(25-113)\end{array}$ & $\begin{array}{l}30.5 \\
(23)\end{array}$ & 0.595 \\
\hline $\begin{array}{l}\text { Log Plasma HIV-1 viral load } \\
\text { median (IQR) }\end{array}$ & $\begin{array}{l}5.90 \\
(5.57-6.0)\end{array}$ & $\begin{array}{l}5.93 \\
(5.39-6.0)\end{array}$ & $\begin{array}{l}5.64 \\
(5.50-6.0)\end{array}$ & 0.729 & $\begin{array}{l}5.86 \\
(5.46-6.0)\end{array}$ & $\begin{array}{l}5.60 \\
(5.41-5.81)\end{array}$ & $\begin{array}{l}5.80 \\
(\mathrm{Q} 1=5.59)\end{array}$ & $0.041^{*}$ \\
\hline
\end{tabular}

* Statistically significant by Kruskal-Wallis test. SD: standard deviation. IQR: interquartile range.

mutant) were found among patients in efavirenz group, while in nevirapine group, there were $44.07 \%$ (26/59) of CYP2B6-516GG genotype, 52.54\% (31/59) of GT genotype and $3.39 \%(2 / 59)$ of TT genotype. The genotype frequencies of CYP2B6-C777A and -A415G in efavirenz and nevirapine groups were $100 \%$ of homozygous mutant AA and $100 \%$ of homozygous wild-type AA, respectively. For $C Y P 2 B 6-C 1459 \mathrm{~T}$, there were $98.5 \%$ $(64 / 65)$ of CC homozygous wild-type and $1.5 \%$ (1/65) of CT heterozygous mutant in efavirenz group, and $91.5 \%$ (54/59) of CC homozygous wild-type, 6.8\% (4/59) of CT heterozygous mutant and $1.7 \%(1 / 59)$ homozygous mutant in nevirapine group. Likewise, the genotype frequencies in CYP3A4-T566C and -C1088T were 100\% of homozygous wild-type TT and homozygous mutant TT, respectively, in both efavirenz and nevirapine groups. For CYP3A4-T878C, there were $95.4 \%(62 / 65)$ of homozygous TT and $4.6 \%(3 / 65)$ of heterozygous TC, and 98.3\% (58/59) of homozygous TT and $1.69 \%(1 / 59)$ of heterozygous TC in efavirenz and nevirapine groups, respectively.

CYP2B6-G516T and CYP3A4-T878C genetic polymorphisms and plasma efavirenz and nevirapine concentrations Among 4 SNPs of CYP2B6-G516T, -C777A, -A415G and $-C 1459 \mathrm{~T}$ being evaluated, the frequencies of wildtype, heterozygous mutant and homozygous mutant were well distributed only in CYP2B6-G516T polymorphism, therefore, the analysis of this gene polymorphism was further done in relation to plasma efavirenz and nevirapine levels. The mean plasma efavirenz concentration in patients with homozygous TT genotype at weeks 6 and 12 of ART and 1 month after rifampicin discontinuation $(10.97 \pm 2.32,13.62 \pm 4.21 \mathrm{mg} / \mathrm{L}$ and $8.48 \pm 1.30 \mathrm{mg} / \mathrm{L}$, respectively) were significantly higher than those with GT genotype $(3.43 \pm 0.29,3.35 \pm 0.27$ $\mathrm{mg} / \mathrm{L}$ and $3.21 \pm 0.22 \mathrm{mg} / \mathrm{L}$, respectively) or GG genotype $(2.88 \pm 0.33,2.45 \pm 0.26$ and $2.08 \pm 0.16 \mathrm{mg} / \mathrm{L}$, respectively) ( $<<0.0001$ ) (Figure $1 \mathrm{a}, \mathrm{b}, \mathrm{c})$. Similar results were found in nevirapine group (Figure 1d, e, f) in that the mean plasma drug concentration of patients with TT genotype at weeks 6 and 12 of ART and 1 month after rifampicin discontinuation (14.09 \pm 9.49, $7.94 \pm 2.76$ and $9.44 \pm 0.17 \mathrm{mg} / \mathrm{L}$, respectively) tended to be higher than those with GT genotype (5.65 \pm 0.54 , $5.58 \pm 0.48$ and $7.03 \pm 0.64 \mathrm{mg} / \mathrm{L}$, respectively) or GG genotype $(5.42 \pm 0.48,5.34 \pm 0.50$ and $6.43 \pm 0.64 \mathrm{mg} /$ $\mathrm{L}$, respectively) $(\mathrm{p}=0.003, \mathrm{p}=0.409$ and $\mathrm{p}=0.448$, respectively).

One month after rifampicin discontinuation, there was a clear trend towards lower plasma efavirenz levels than those during concomitant rifampicin at week 6 and 12 of ART regardless of CYP2B6 G516T genotypes. In fact, when we evaluated effects of rifampicin on plasma efavirenz levels without stratifying CYP2B6 G516T polymorphisms, the plasma efavirenz levels after rifampicin 


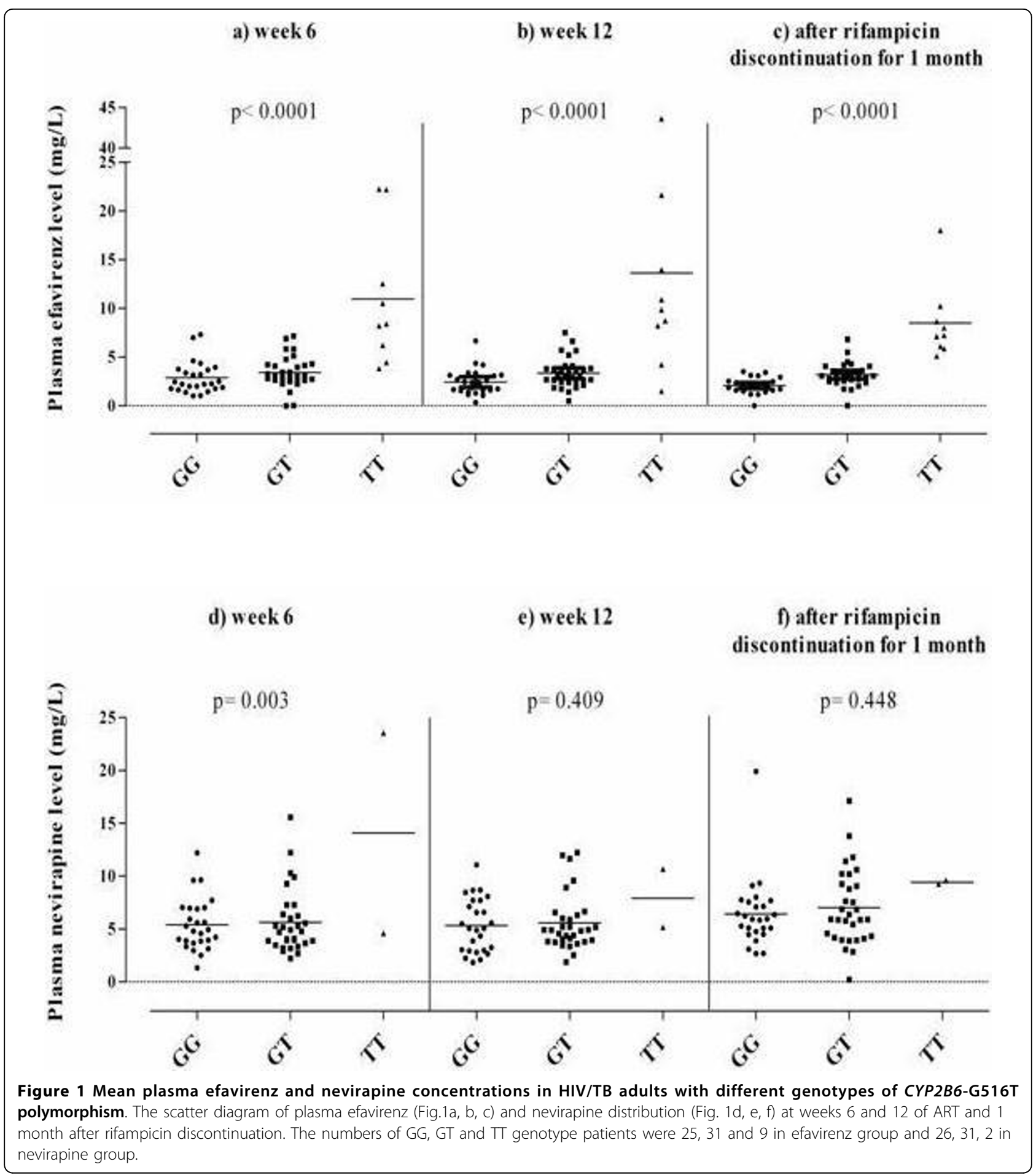

discontinuation $(3.5 \pm 2.67 \mathrm{mg} / \mathrm{L})$ were significantly lower than those at week $6(4.26 \pm 3.96 \mathrm{mg} / \mathrm{L})(\mathrm{p}=$ $0.043)$ and tended to be lower than those at week 12 $(4.42 \pm 5.97 \mathrm{mg} / \mathrm{L})(\mathrm{p}=0.133)$. In contrast, plasma nevirapine levels at 1 month after rifampicin discontinuation $(6.84 \pm 3.4 \mathrm{mg} / \mathrm{L})$ were significantly higher than those at week $6(5.83 \pm 3.6 \mathrm{mg} / \mathrm{L}, \mathrm{p}=0.034)$ and those at week $12(5.56 \pm 2.63 \mathrm{mg} / \mathrm{L}, \mathrm{p}<0.001)$. The reason for these discrepant results on effects of rifampicin on plasma efavirenz and nevirapine levels is not clear at present. Further studies including evaluation of plasma drug levels at time points other than 12-hour post-dose would be thus necessary. Nevertheless, we at least can conclude that the magnitude of effects on plasma 
efavirenz and nevirapine levels by rifampicin was much smaller than that by CYP2B6 516 TT genotype.

With respect to $C Y P 3 A 4$, the analysis was done in only CYP3A4-T878C, since there was no variation at the CYP3A4-T878C and -C1088T in our study subjects. The results showed that the mean plasma efavirenz concentration at weeks 6 and 12 of ART and 1 month after rifampicin discontinuation were $4.00 \pm 0.42,4.20 \pm 0.72$ and $3.48 \pm 0.34 \mathrm{mg} / \mathrm{L}$, respectively, in patients with homozygous TT genotype and $9.62 \pm 6.35,8.97 \pm 6.33$ and $3.87 \pm 1.69 \mathrm{mg} / \mathrm{L}$, respectively, in those with heterozygous TC genotype. Similarly, the mean plasma nevirapine concentration at weeks 6 and 12 of ART and 1 month after rifampicin discontinuation were $5.85 \pm 0.48$, $5.50 \pm 0.34$ and $6.80 \pm 0.45 \mathrm{mg} / \mathrm{L}$, respectively, in patients with homozygous TT genotype, and 4.8, 8.69 and $9.12 \mathrm{mg} / \mathrm{L}$, respectively, in one patient with heterozygous mutant TC genotype. Although there was a trend towards higher plasma drug levels in patients with heterozygous mutant TC genotype, appropriate statistical evaluation of this difference was difficult due to small numbers of heterozygous mutant TC.

\section{CD4 T cell counts and HIV-1 viral load among patients with CYP2B6-G516T genotypes}

The CD4 $\mathrm{T}$ cell counts among patients carrying different $C Y P 2 B 6$ genotypes in efavirenz and nevirapine groups are shown in Figure 2. The number of CD4 T cells in patients with TT, GT and GG genotypes increased in a similar manner at all time points at weeks 12, 24, 36 and 48 of ART compared to the baseline in both efavirenz and nevirapine groups. No significant difference in median CD4 T cell counts of each genotype at different time points was seen in efavirenz group $(\mathrm{p}=$ $0.818,0.838,0.783,0.753$ and 0.587 for baseline, weeks $12,24,36$ and 48 of ART, respectively), whereas, in nevirapine group, the median CD4 $\mathrm{T}$ cell counts of patients with TT genotype seem to be lower than those with the other two genotypes at different time points, although this difference did not reach statistical significance $(\mathrm{p}=0.595,0.182,0.554,0.573$ and 0.494 , respectively) (Figure 2a, b).

As shown in Table 2, when the proportion of patients with HIV-1 RNA level $<50$ copies/mL $(\log 1.69)$ were compared among CYP2B6-G516T genotypes at week 12 of ART, $88.89 \%$ (8/9) of patients with TT genotype in efavirenz group could achieve the HIV-1 RNA levels $<50$ copies $/ \mathrm{mL}$, which were higher than those with GT genotype $(77.42 \%, 24 / 31)$ and GG genotype $(68 \%, 17 /$ $25)$, although this difference was not statistically significant $(\mathrm{p}=0.430)$. Similarly, in nevirapine group, $100 \%$ $(2 / 2)$ of those with TT genotype, $70.97 \%(23 / 31)$ of those with GT genotype and $60 \%(15 / 26)$ of those with GG genotype could achieve the HIV-1 RNA levels $<50$
copies/mL, but this difference also did not reach statistical significance $(\mathrm{p}=0.288)$ due to small numbers of patients with homozygous TT genotype in this study. At weeks 24,36 and 48 of ART, nearly all the patients achieved undetectable viral load, since viral load were not detected in $95.38 \%(62 / 65), 93.65 \%(59 / 63)$ and $87.9 \%(54 / 62)$, respectively, of efavirenz group and 96.55\% (56/58), 94.64\% (53/56) and 94.64\% (53/56), respectively, of nevirapine group.

\section{Discussion}

This is the first report to demonstrate the effects of CYP2B6-G516T and CYP3A4-T878C polymorphisms on plasma efavirenz and nevirapine concentrations in rifampicin-treated HIV/TB co-infected Thai adults. The results indicated that the wide interindividual variability of efavirenz concentrations is strongly influenced by CYP2B6-516TT genotype by the finding of significantly higher plasma efavirenz concentration at weeks 6 and 12 of ART and 1 month after rifampicin discontinuation compared to those with GT or GG genotype. Likewise, it seems to be that this CYP2B6-516TT would also influence nevirapine concentrations, although it was less pronounced probably due to the small samples size of homozygous mutant TT in our sample set. The present results were in line with the previous report on efavirenz pharmacokinetics when co-administration with rifampicin in HIV/TB co-infected Indian [26,27] and Ghana patients [28] in that plasma efavirenz was highest in patients with CYP2B6-516TT genotype when compared to those with GT or GG genotypes. While the heterozygous TC mutant in CYP3A4-T878C in this study seems to have some effects on plasma drug concentrations in patients at weeks 6 and 12 of ART and 1 month after rifampicin discontinuation in both efavirenz and nevirapine groups, further statistical analysis was not done due to the relatively less variation of CYP3A4 among Thai adults in this study. Further investigation should include a larger sample size with varying genotypes in order to draw a definite conclusion on the effect of CYP3A4 variations.

In this study, the frequency of CYP2B6-G516T among 124 Thai adults was $8.9 \%$, which was close to that of our recent study on $237 \mathrm{HIV}$-infected Thai adults with different rate of CD4 T cell recovery after ARV treatment (9.7\%) (submitted for publication) and slightly lower than what has been reported in Thai children (11\%) [22]. Comparing to the other ethnic groups, it was higher than those of Japanese (3.3\%) [15] and Caucasian (6\%) [14], but lower than that of African-American (20\%) [21] or African population (23\%) [28,29]. Although the frequencies of CYP2B6-G516T were different among populations or ethnicity, the pharmacogenetic studies reported so far in HIV patients 

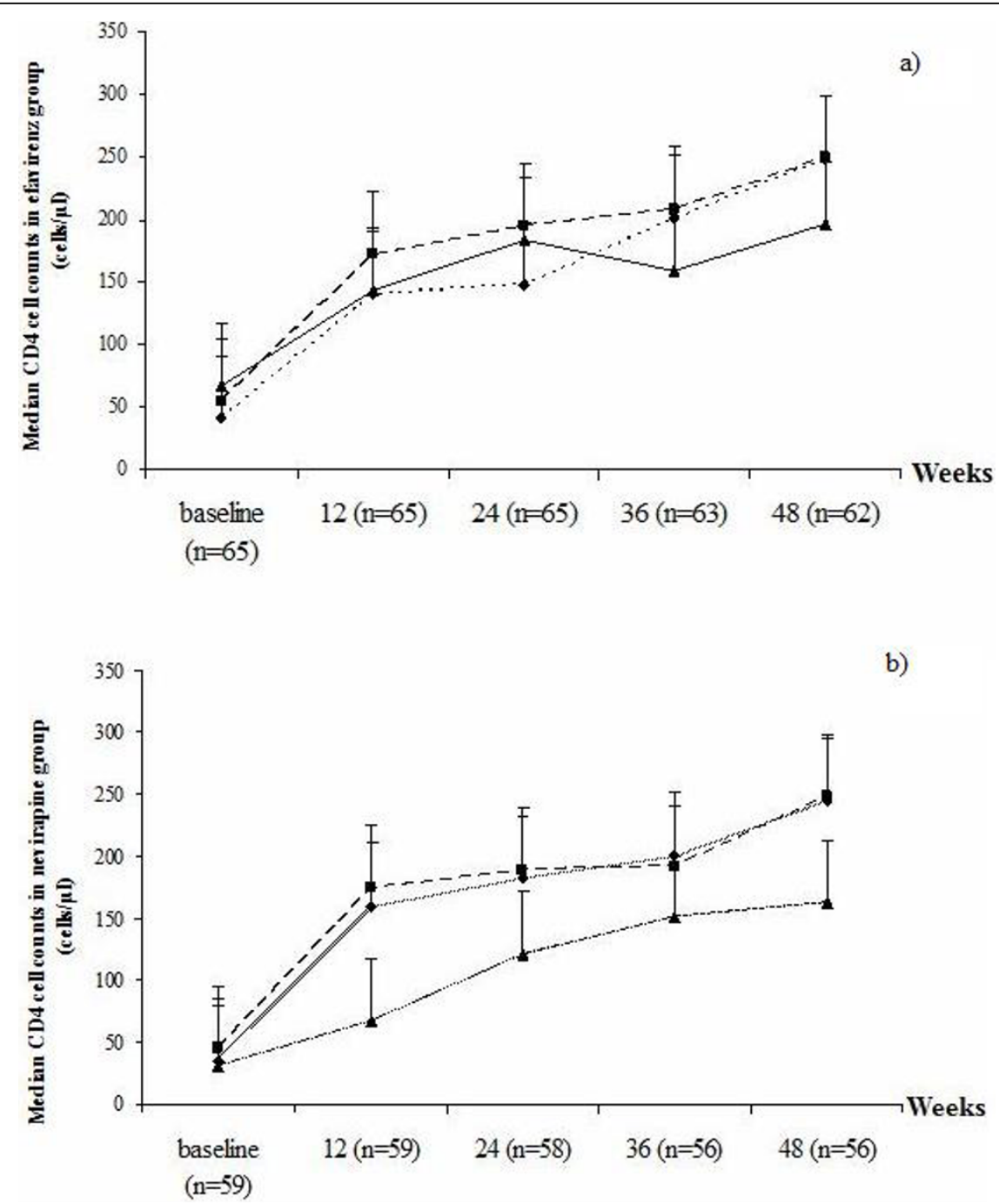

Figure 2 Median CD4 T cell counts among HIV/TB adults with CYP2B6-G516T polymorphism at different time points. (Black diamond) GG genotype, (Black square), GT genotype, (Black triangle) TT genotype in efavirenz (a) and nevirapine groups (b) at baseline, 12, 24, 36 and 48 weeks of ART.

Table 2 Number of patients with plasma HIV-1 RNA $<50$ copies/ml at week 12 of ART.

\begin{tabular}{|c|c|c|c|c|c|c|c|c|}
\hline & \multicolumn{4}{|c|}{$\begin{array}{l}\text { Efavirenz group }(\mathrm{N}=65) \\
\text { CYP2B6-G516T }\end{array}$} & \multicolumn{4}{|c|}{$\begin{array}{l}\text { Nevirapine group }(\mathrm{N}=59) \\
\text { CYP2B6-G516T }\end{array}$} \\
\hline & $\begin{array}{l}\mathrm{GG} \\
\mathrm{n}=25\end{array}$ & $\begin{array}{l}\mathrm{GT} \\
\mathrm{n}=31\end{array}$ & $\begin{array}{l}\text { TT } \\
n=9\end{array}$ & p-value* & $\begin{array}{l}\mathrm{GG} \\
\mathrm{n}=26\end{array}$ & $\begin{array}{l}\mathrm{GT} \\
\mathrm{n}=31\end{array}$ & $\begin{array}{l}\mathrm{TT} \\
\mathrm{n}=2\end{array}$ & $p$-value $* *$ \\
\hline $\begin{array}{l}\text { No. of patients } \\
(\%)\end{array}$ & $\begin{array}{l}17 \\
(68)\end{array}$ & $\begin{array}{l}24 \\
(77.42)\end{array}$ & $\begin{array}{l}8 \\
(88.89)\end{array}$ & 0.430 & $\begin{array}{l}15 \\
(60)\end{array}$ & $\begin{array}{l}23 \\
(70.97)\end{array}$ & $\begin{array}{l}2 \\
(100)\end{array}$ & 0.288 \\
\hline
\end{tabular}

* Chi-square test

** Fisher's exact test

demonstrated that CYP2B6 516TT was definitely associated with plasma efavirenz concentration $[15,19,21,29,30]$. The findings of CYP2B6 516TT genotype in the present study support its effect on plasma efavirenz concentration in different ethnic group and gave additional information of this SNP on nevirapine based-ART when co-administered with rifampicin. The recent pharmacogenetic study in HIV patients co-administrated with efavirenz and rifampicin demonstrated that patients carrying TT genotype had significantly higher mean plasma efavirenz but lower oral clearance [28], indicating that rifampicin does not fully reverse the poor metabolizer phenotype and that TT genotype can be used to identify poor metabolizers of efavirenz even 
in patients co-administrated with rifampicin. Consistently, the present results also indicated that rifampicin coadministration in HIV/TB infected patients did not significantly alter plasma efavirenz and nevirapine levels in patients with TT genotype $(\mathrm{p}>0.05)$. Other possible factors that might affect the plasma drug levels could be excluded since they were carefully controlled.

Although rifampicin can cause the decrease in NNRTI concentrations, the mean plasma efavirenz and nevirapine concentrations in all studied patients with TT, GT and GG genotypes had plasma drug levels above the minimum recommendation $(1 \mathrm{mg} / \mathrm{L}$ for efavirenz and $3.4 \mathrm{mg} / \mathrm{L}$ for nevirapine). One important conclusion from our recent prospective and randomized clinical trial in patients with concurrent HIV/TB receiving rifampicin [24] is that the standard dosage of efavirenz $600 \mathrm{mg}$ or nevirapine $400 \mathrm{mg}$ per day and co-administration with rifampicin was adequate for HIV-1 suppression, however, variation in the plasma drug levels in some patients were found, which might be due to the genetic variations among individuals. Although we reported recently that high body weights of the patients were associated with a low efavirenz $C_{12}$ at weeks 6 and 12 of ART [31], the present results demonstrated that the body weights did not differ among patients with different genotypes of CYP2B6 G516T polymorphism. The present results thus demonstrated that rifampicin has very small effects on efavirenz and nevirapine plasma drug. The advantage of our present study over previous studies is that plasma efavirenz and nevirapine concentrations during co-administration of rifampicin could be compared with those without rifampicin after completing $\mathrm{TB}$ drug treatment.

In general, the high plasma efavirenz and nevirapine levels could lead to the adverse effect such as rash, hepatitis, and neuropsychological toxicity [32,33]. In order to reduce such adverse effects, several studies attempted to test the feasibility of genotype-based dose reduction of efavirenz in African-American [34] and Japanese HIV infected patients [35] and showed that efavirenz dose reduction is feasible and can reduce efavirenz-associated central nervous system symptoms in homozygotes of CYP2B6-G516T. Although patients with CYP2B6-516TT in our cohort had obviously high plasma efavirenz levels at all time points and certain degree of central nervous system and psychiatric manifestations, they were all well tolerated with the adverse effects. The adverse drug events have not recorded in nevirapine based treatment probably due to the limited number of patients with homozygous TT. Since there were 7 cases who could not complete the study due to side effects [24] it is necessary to determine CYP2B6 G516T genotypes of these individuals in order to know whether CYP2B6-516TT homozygote in Thailand were all well tolerated with the adverse effects of efavirenz and nevirapine.

With respect to possible correlation of the variations in plasma efavirenz and nevirapine levels with the treatment outcome, our results indicated that the patients with CYP2B6 516TT genotype had a higher frequency of viral load suppression at week 12 of ART than those with GT and GG genotype. The CD4 T cell counts increased after treatment at all time points which were correlated with HIV-1 viral load reduction. When the effect of different CYP2B6-G516T genotypes was analysed, no difference was observed among patients with TT, GT and GG genotypes in both efavirenz and nevirapine groups. Collectively, it is indicated that the efavirenz and nevirapine-based ART co-administered with rifampicin are well correlated with virological and immunological outcomes in patients undergoing treatment for HIV and TB.

In summary, the CYP2B6 and CYP3A4 polymorphisms were analysed, for the first time, in HIV/TB co-infected Thai adults receiving efavirenz and nevirapine basedART co-administered with rifampicin and the results indicated that only $516 \mathrm{G}>\mathrm{T}$ in $C Y P 2 B 6$ gene, but not CYP3A4 gene polymorphism, gave the significant effects on plasma drug levels. Only small effects of rifampicin on efavirenz and nevirapine plasma concentration were observed. However, for further investigation, other SNPs such as CYP2B6 T983C or TGATC-CYP2B6 haplotypes which were shown to influence the NNRTI plasma drug levels $[23,36,37]$ should be taken into account and larger sample size with varying genotypes should be included.

\section{Conclusions}

CYP2B6-TT genotype had effects on both the plasma efavirenz and nevirapine concentrations in HIV/TB patients when co-administered with rifampicin. The information might be useful for better treatment of patients with HIV or HIV/TB.

\section{Acknowledgements}

We thank the patients for their kind participation in the study. This study was supported by the Royal Golden Jubilee Ph.D. Program (Grant No. PHD/ 0094/2551) of the Thailand Research Fund; Faculty of Graduate Studies in the academic year 2008-2009 and Faculty of Tropical Medicine, Mahidol University; the Health Sciences foundation and the Ministry of Education, Culture, Sports, Sciences and Technology, Japan and Bamrasnaradura Infectious Diseases Institute (BIDI), Thailand. We thank Dr. Kiat Ruxrungtham the HIV-Netherlands-Australia-Thailand (HIV-NAT) Research Pharmacokinetic Laboratory for determining plasma drug levels, Dr. Surakameth Mahasirimongkol, Department of Medical Sciences, Ministry of Public Health for advice on SNP analysis, Dr. Jaranit Kaewkungwal and Mr. Irwin Chavez for advice on statistical analysis, Ms. Tippawan Rattanatham, Ms. Samruay Nilkamhang, and Ms. Supeda Tongyen, BIDI for their help in recruiting patients.

\section{Author details}

${ }^{1}$ Department of Microbiology and Immunology, Faculty of Tropical Medicine, Mahidol University, Bangkok, Thailand. ${ }^{2}$ Bamrasnaradura Infectious Diseases 
Institute, Department of Disease Control, Ministry of Public Health, Nonthaburi, Thailand. ${ }^{3}$ National Institute of Health, Department of Medical Sciences, Ministry of Public Health, Nonthaburi, Thailand. ${ }^{4}$ Research Institute of Microbial Disease, Osaka University, Osaka, Japan.

\section{Authors' contributions}

SU, SL, WM, NW, TK, SK participated in the study design. SU performed genotyping, CD4 counts and HIV-1 viral load determination, analysed the data and drafted the manuscript. EEN and NW took part in genotyping. SL and WM coordinated the study. TS and SK revised and finalised the manuscript. All authors read and approved the final manuscript.

\section{Author's information}

SU is a Ph.D. candidate at the Faculty of Tropical Medicine, Mahidol University, Bangkok and deputy chief of Immunology and Virology Laboratory, Bamrasnaradura Infectious Diseases Institute (BIDI), Nonthaburi, Thailand. SL is a chief of Immunology and Virology Laboratory, BIDI. WM is a clinician who is taking care of HIV-1 infected patients and a principle investigator of a randomized control trial of efavirenz-based versus nevirapine-based antiretroviral therapy among HIV-infected patients receiving rifampicin. NW is the chief of Genetic Research Laboratory, National Institute of Health. TK is an assistant professor of Department of Microbiology and Immunology, Faculty of Tropical Medicine, Mahidol University. EEN is an assistant professor of Osaka University, Japan. TS is a professor of Osaka University and works on HIV-1 infection and host genome. SK is a professor of Department of Microbiology and Immunology, Faculty of Tropical Medicine, Mahidol University who does the research on malaria, TB and HIV and the supervisor of SU.

\section{Competing interests}

The authors declare that they have no competing interests.

Received: 15 November 2009 Accepted: 26 March 2010

Published: 26 March 2010

\section{References}

1. Cain KP, Anekthananon T, Burapat C, Akksilp S, Mankhatitham W, Srinak C, Nateniyom S, Sattayawuthipong W, Tasaneeyapan T, Varma JK: Causes of death in HIV-infected persons who have tuberculosis, Thailand. Emerg Infect Dis 2009, 15:258-264.

2. Manosuthi W, Chottanapand S, Thongyen S, Chaovavanich A, Sungkanuparph S: Survival rate and risk factors of mortality among HIV/ tuberculosis-coinfected patients with and without antiretroviral therapy. J Acquir Immune Defic Syndr 2006, 43:42-46.

3. Hammer SM, Saag MS, Schechter M, Montaner JS, Schooley RT, Jacobsen DM, Thompson MA, Carpenter CC, Fischl MA, Gazzard BG, Gatell JM, Hirsch MS, Katzenstein DA, Richman DD, Vella S, Yeni PG, Volberding PA: Treatment for adult HIV infection: 2006 recommendations of the International AIDS Society-USA panel. JAMA 2006, 296:827-843.

4. Ward BA, Gorski JC, Jones DR, Hall SD, Flockhart DA, Desta Z: The cytochrome P450 2B6 (CYP2B6) is the main catalyst of efavirenz primary and secondary metabolism: implication for HIV/AIDS therapy and utility of efavirenz as a substrate marker of CYP2B6 catalytic activity. J Pharmacol Exp Ther 2003, 306:287-300.

5. Lopez-Cortes LF, Ruiz-Valderas R, Viciana P, Alarcon-Gonzalez A, GomezMateos J, Leon-Jimenez E, Sarasanacenta M, Lopez-Pua Y, Pachon J: Pharmacokinetic interactions between efavirenz and rifampicin in HIVinfected patients with tuberculosis. Clin Pharmacokinet 2002, 41:681-690.

6. Patel A, Patel K, Patel J, Shah N, Patel B, Rani S: Safety and antiretroviral effectiveness of concomitant use of rifampicin and efavirenz for antiretroviral-naive patients in India who are coinfected with tuberculosis and HIV-1. J Acquir Immune Defic Syndr 2004, 37:1166-1169.

7. Ribera E, Pou L, Lopez RM, Crespo M, Falco V, Ocana I, Ruiz I, Pahissa A: Pharmacokinetic interaction between nevirapine and rifampicin in HIVinfected patients with tuberculosis. J Acquir Immune Defic Syndr 2001, 28:450-453.

8. Desta Z, Saussele T, Ward B, Blievernicht J, Li L, Klein K, Flockhart DA, Zanger UM: Impact of CYP2B6 polymorphism on hepatic efavirenz metabolism in vitro. Pharmacogenomics 2007, 8:547-558.
9. Pinzani V, Faucherre V, Peyriere H, Blayac JP: Methadone withdrawal symptoms with nevirapine and efavirenz. Ann Pharmacother 2000, 34:405-407.

10. Erickson DA, Mather G, Trager WF, Levy RH, Keirns JJ: Characterization of the in vitro biotransformation of the HIV-1 reverse transcriptase inhibitor nevirapine by human hepatic cytochromes P-450. Drug Metab Dispos 1999, 27:1488-1495.

11. Cohen K, Grant A, Dandara C, Mcllleron H, Pemba L, Fielding K, Charalombous S, Churchyard G, Smith P, Maartens G: Effect of rifampicinbased antitubercular therapy and the cytochrome P450 2B6 516G>T polymorphism on efavirenz concentrations in adults in South Africa. Antivir Ther 2009, 14:687-695.

12. Cabrera SE, Santos D, Valverde MP, Dominguez-Gil A, Gonzalez F, Luna G, Garcia MJ: Influence of the cytochrome P450 2B6 genotype on population pharmacokinetics of efavirenz in human immunodeficiency virus patients. Antimicrob Agents Chemother 2009, 53:2791-2798.

13. Cohen K, van Cutsem G, Boulle A, Mcllleron H, Goemaere E, Smith PJ, Maartens G: Effect of rifampicin-based antitubercular therapy on nevirapine plasma concentrations in South African adults with HIVassociated tuberculosis. J Antimicrob Chemother 2008, 61:389-393.

14. Lang T, Klein K, Fischer J, Nussler AK, Neuhaus P, Hofmann U, Eichelbaum M, Schwab M, Zanger UM: Extensive genetic polymorphism in the human CYP2B6 gene with impact on expression and function in human liver. Pharmacogenetics 2001, 11:399-415.

15. Tsuchiya K, Gatanaga H, Tachikawa N, Teruya K, Kikuchi Y, Yoshino M, Kuwahara T, Shirasaka T, Kimura S, Oka S: Homozygous CYP2B6 *6 (Q172H and K262R) correlates with high plasma efavirenz concentrations in HIV1 patients treated with standard efavirenz-containing regimens. Biochem Biophys Res Commun 2004, 319:1322-1326.

16. Saitoh A, Sarles E, Capparelli E, Aweeka F, Kovacs A, Burchett SK, Wiznia A, Nachman S, Fenton T, Spector SA: CYP2B6 genetic variants are associated with nevirapine pharmacokinetics and clinical response in HIV-1-infected children. AIDS 2007, 21:2191-2199.

17. Powers V, Ward J, Gompels M: CYP2B6 G516T genotyping in a UK cohort of HIV-positive patients: polymorphism frequency and influence on efavirenz discontinuation. HIV Med 2009, 10:520-523.

18. Haas DW, Gebretsadik T, Mayo G, Menon UN, Acosta EP, Shintani A, Floyd M, Stein CM, Wilkinson GR: Associations between CYP2B6 polymorphisms and pharmacokinetics after a single dose of nevirapine or efavirenz in African americans. J Infect Dis 2009, 199:872-880.

19. King J, Aberg JA: Clinical impact of patient population differences and genomic variation in efavirenz therapy. AIDS 2008, 22:1709-1717.

20. Saitoh A, Fletcher CV, Brundage R, Alvero C, Fenton T, Hsia K, Spector SA: Efavirenz pharmacokinetics in HIV-1-infected children are associated with CYP2B6-G516T polymorphism. J Acquir Immune Defic Syndr 2007, 45:280-285.

21. Haas DW, Ribaudo HJ, Kim RB, Tierney C, Wilkinson GR, Gulick RM, Clifford DB, Hulgan T, Marzolini C, Acosta EP: Pharmacogenetics of efavirenz and central nervous system side effects: an Adult AIDS Clinical Trials Group study. AIDS 2004, 18:2391-2400.

22. Puthanakit T, Tanpaiboon P, Aurpibul L, Cressey TR, Sirisanthana V: Plasma efavirenz concentrations and the association with CYP2B6-516G>T polymorphism in HIV-infected Thai children. Antivir Ther 2009, 14:315-320.

23. Chantarangsu S, Cressey TR, Mahasirimongkol S, Capparelli E, Tawon Y, Ngo-Giang-Huong N, Jourdain G, Lallemant M, Chantratita W: Influence of CYP2B6 polymorphisms on the persistence of plasma nevirapine concentrations following a single intra-partum dose for the prevention of mother to child transmission in HIV-infected Thai women. J Antimicrob Chemother 2009.

24. Manosuthi W, Sungkanuparph S, Tantanathip P, Lueangniyomkul A, Mankatitham W, Prasithsirskul W, Burapatarawong S, Thongyen S, Likanonsakul S, Thawornwa U, Prommool V, Ruxrungtham K: A randomized trial comparing plasma drug concentrations and efficacies between 2 nonnucleoside reverse-transcriptase inhibitor-based regimens in HIVinfected patients receiving rifampicin: the N2R Study. Clin Infect Dis 2009, 48:1752-1759.

25. Hollanders RM, van Ewijk-Beneken Kolmer EW, Burger DM, Wuis EW, Koopmans PP, Hekster YA: Determination of nevirapine, an HIV-1 nonnucleoside reverse transcriptase inhibitor, in human plasma by reversed- 
phase high-performance liquid chromatography. I Chromatogr B Biomed Sci Appl 2000, 744:65-71.

26. Ramachandran G, Hemanth Kumar AK, Rajasekaran S, Kumar P, Ramesh K, Anitha S, Narendran G, Menon P, Gomathi C, Swaminathan S: CYP2B6 G516T polymorphism but not rifampin coadministration influences steady-state pharmacokinetics of efavirenz in human immunodeficiency virus-infected patients in South India. Antimicrob Agents Chemother 2009, 53:863-868.

27. Ramachandran G, Ramesh K, Hemanth Kumar AK, Jagan I, Vasantha M, Padmapriyadarsini C, Narendran G, Rajasekaran S, Swaminathan S: Association of high T allele frequency of CYP2B6 G516T polymorphism among ethnic south Indian HIV-infected patients with elevated plasma efavirenz and nevirapine. J Antimicrob Chemother 2009, 63:841-843.

28. Kwara A, Lartey M, Sagoe KW, Xexemeku F, Kenu E, Oliver-Commey J, Boima V, Sagoe A, Boamah I, Greenblatt DJ, Court MH: Pharmacokinetics of efavirenz when co-administered with rifampin in TB/HIV co-infected patients: pharmacogenetic effect of CYP2B6 variation. J Clin Pharmacol 2008, 48:1032-1040

29. Wang J, Sonnerborg A, Rane A, Josephson F, Lundgren S, Stahle L, Ingelman-Sundberg M: Identification of a novel specific CYP2B6 allele in Africans causing impaired metabolism of the HIV drug efavirenz. Pharmacogenet Genomics 2006, 16:191-198.

30. Rotger M, Tegude H, Colombo S, Cavassini M, Furrer H, Decosterd L, Blievernicht J, Saussele T, Gunthard HF, Schwab M, Eichelbaum M, Telenti A, Zanger UM: Predictive value of known and novel alleles of CYP2B6 for efavirenz plasma concentrations in HIV-infected individuals. Clin Pharmacol Ther 2007, 81:557-566.

31. Manosuthi W, Sungkanuparph S, Tantanathip P, Mankatitham W, Lueangniyomkul A, Thongyen S, Eampokarap B, Uttayamakul S, Suwanvattana P, Kaewsaard S, Ruxrungtham K: Body weight cutoff for daily dosage of efavirenz and 60-week efficacy of efavirenz-based regimen in human immunodeficiency virus and tuberculosis coinfected patients receiving rifampin. Antimicrob Agents Chemother 2009, 53:4545-4548.

32. Kappelhoff BS, van Leth F, Robinson PA, MacGregor TR, Baraldi E, Montella F, Uip DE, Thompson MA, Russell DB, Lange JM, Beijnen JH, Huitema AD: Are adverse events of nevirapine and efavirenz related to plasma concentrations? Antivir Ther 2005, 10:489-498.

33. Ananworanich J, Moor Z, Siangphoe U, Chan J, Cardiello P, Duncombe C, Phanuphak P, Ruxrungtham K, Lange J, Cooper DA: Incidence and risk factors for rash in Thai patients randomized to regimens with nevirapine, efavirenz or both drugs. AIDS 2005, 19:185-192.

34. Torno MS, Witt MD, Saitoh A, Fletcher CV: Successful use of reduced-dose efavirenz in a patient with human immunodeficiency virus infection: case report and review of the literature. Pharmacotherapy 2008, 28:782-787.

35. Gatanaga H, Hayashida T, Tsuchiya K, Yoshino M, Kuwahara T, Tsukada H, Fujimoto K, Sato I, Ueda M, Horiba M, Hamaguchi M, Yamamoto M, Takata N, Kimura A, Koike T, Gejyo F, Matsushita S, Shirasaka T, Kimura S, Oka S: Successful efavirenz dose reduction in HIV type 1-infected individuals with cytochrome P450 2B6*6 and *26. Clin Infect Dis 2007, 45:1230-1237.

36. Kwara A, Lartey M, Sagoe KW, Kenu E, Court MH: CYP2B6, CYP2A6 and UGT2B7 genetic polymorphisms are predictors of efavirenz mid-dose concentration in HIV-infected patients. AIDS 2009, 23:2101-2106.

37. Wyen $C$, Hendra H, Vogel M, Hoffmann C, Knechten H, Brockmeyer NH, Bogner JR, Rockstroh J, Esser S, Jaeger H, Harrer T, Mauss S, van Lunzen J, Skoetz N, Jetter A, Groneuer C, Fatkenheuer G, Khoo SH, Egan D, Back DJ, Owen A: Impact of CYP2B6 983T>C polymorphism on non-nucleoside reverse transcriptase inhibitor plasma concentrations in HIV-infected patients. J Antimicrob Chemother 2008, 61:914-918.

doi:10.1186/1742-6405-7-8

Cite this article as: Uttayamakul et al:: Effects of CYP2B6 G516T

polymorphisms on plasma efavirenz and nevirapine levels when co-administered with rifampicin in HIV/TB co-infected Thai adults. AIDS Research and Therapy 2010 7:8.

\section{Submit your next manuscript to BioMed Central and take full advantage of:}

- Convenient online submission

- Thorough peer review

- No space constraints or color figure charges

- Immediate publication on acceptance

- Inclusion in PubMed, CAS, Scopus and Google Scholar

- Research which is freely available for redistribution 